\title{
Exploring Education Culture by Employing Hofstede's Cultural Dimensions to Evaluate the Effectiveness of the Current ERP Training Approach in Thailand
}

\author{
Monta Chayakonvikom ${ }^{1}$, Parin Fuangvut ${ }^{2}$, Stephen Cannell ${ }^{1}$ \\ ${ }^{1}$ Durakij Pundit University International College (DPUIC), Bangkok, Thailand \\ ${ }^{2}$ Mahidol University International College, Bangkok, Thailand \\ Correspondence: Monta Chayakonvikom, Durakij Pundit University International College (DPUIC), Bangkok, Thailand.
}

Received: August 1, 2016 Accepted: August 9, $2016 \quad$ Online Published: August 18, 2016

doi:10.11114/jets.v4i10.1775 URL: http://dx.doi.org/10.11114/jets.v4i10.1775

\begin{abstract}
ERP training is a critical success factor in ERP implementation. The current ERP training was largely ineffective and caused user resistance and ERP implementation failure. The objective of this paper is to investigate whether the current ERP training approach can accommodate the cultural learning behaviors of end-users. Hofstede's cultural dimensions are employed to explain end-user dissatisfaction toward the current ERP training approach. The research is founded on the idea that different people learn in different ways, and cultural diversity may also influence how they learn and are taught. The current ERP training approach was design based on a Western learning culture and applied without concern for different learning cultures, which may be problematic. To achieve the objective, a qualitative method was adopted in this research. In-depth interviews were conducted with seventy-two end-users from twenty-two companies that had adopted an ERP system and had experienced ERP training in a Thai context during the implementation phase. The findings support the assumption by showing that the current ERP training approach did not accommodate Thai cultural learning behaviors in many areas. The content in this paper is a part of a comprehensive research to propose an ERP training framework to support the variety of end-user learning styles and different cultural learning behaviors.
\end{abstract}

Keywords: educational culture, individual learning style, current ERP training approach, Hofstede's cultural dimensions

\section{Introduction}

\subsection{Introducing the Problem and Exploring the Importance of the Problem}

Enterprise Resource Planning (ERP) systems, which have been widely used since the 1960s, are information systems that attempt to integrate the broad set of organizational business processes into a computer and database system. ERP systems provide the opportunity for all business units to share information and communication. Furthermore, an ERP system reduces the problem of maintaining the legacy system and also improves the efficiency of management (Kilic, Zaim \& Delen, 2015). Implementing an ERP system requires a lot of resources and is time consuming. Most ERP implementations face failure. A significant reason for ERP failure is user resistance as a quarter of ERP projects face user resistance. However, ineffective training is the most cited cause of user resistance and is a critical success factor in an ERP implementation project (Aslam, 2010, Ram \& Corkindale, 2014).

Many factors have been investigated to improve ERP training efficiency, but insufficient attention has been given to cross cultural education issues, which have been suggested as areas for future research (Dwivedi, et al., 2015, Hawari \& Heeks, 2010). The ERP training approach most widely used in current ERP implementation projects is that which is embedded in ERP implementation methodology and is designed by ERP vendors. Most ERP systems originate from the West, and seem to be based on Western cultural perceptions, but are applied in all cultural contexts. Current ERP training does not have training instructions for different education cultures (Shahin, Sadri \& Gazor, 2010), in particular, in Asia, where there are differences in learning culture (Marambe, Vermunt \& Boshuizen, 2012). This might be the cause of poor training efficiency and should be investigated. The findings of a previous empirical study conducted by the researcher revealed the current ERP training failed to transfer knowledge to end-users about how to use the ERP system properly. Four areas of the current ERP training, about which end-users were dissatisfied, are the training 
method, the training content, the training and user manuals, and the training time allocation. Research could attempt to explain why the four areas of the current ERP training approach were not satisfactory for end-users and whether it was related to cultural learning behavior (Chayakonvikom, Fuangvut \& Prinyapol, 2016).

Therefore, the aim of this paper is to explore the cultural learning behavior of end-users in a Thai context, and to explain the issues and dissatisfaction about the current ERP training approach. The concept of culture in education with reference to Hofstede's cultural dimensions was applied in this paper. A better understanding of the cultural background and learning behavior in education is required to increase the success rate of ERP training including a reduction in user resistance and the failure of ERP implementation projects. Additionally, this can help researchers to assess the impact of cultural dimensions on the current ERP training approach. This information will be used as evidence to be considered in ERP instructional design, which should be culturally inclusive and able to accommodate various learning styles.

\subsection{Culture through Education in a Thai Context}

Cultural background strongly affects learning style because culture-based educational experiences tend to influence the way learners participate in education. Hofstede's work on culture is the most widely cited and is a valuable insight into the dynamics of cross-cultural relationships, including culture in education. The cultural dimensions have also been linked by Hofstede (1986) to educational culture. However, Thailand's culture contrasts with the West, especially in terms of educational culture (Meissonier, Houze \& Bessiere, 2013). The concepts of culture in Thai education with reference to Hofstede's cultural dimensions are described in the following section.

\subsubsection{Power Distance}

This dimension represents the power distribution inequality in society. Thailand scored 64 on the power distance index, which is quite high, but slightly lower than the average of Asian countries. People show loyalty and respect for superiors in exchange for protection and guidance, which relates to hierarchical control, including a paternalistic management structure. Countries with high power distance are characterized by certain social hierarchies, which are acceptable to the society. Consequently, the education system is largely a teacher-centered system, in which teachers are ranked higher than students in terms of society and their authority. Students are likely to depend on the teachers, who are qualified as experts to transfer knowledge and initiate communication. Moreover, teachers are treated with respect (Bae, Qian, Miao \& Fiet, 2014).

Thailand has a high power distance culture which is strongly evident in education. The traditional teacher-centered education system reflects high power distance in the classroom. Teachers are expected to lead the class, and learners expect to be told what to do and how to do it. Consequently, Thai students are more passive, and two-way communication with the teacher is discouraged. "Kreng-Jai", which is a unique feature of Thai culture, is a difficult concept for Westerners to understand. "Kreng-Jai" in a Thai hierarchical relationship is acceptance without argument from a lower status individual based on respect, the maintenance of feelings and face consideration. Teachers are respected and should not to be challenged or contradicted publicly. It is more difficult for learners to express opinions in class or defer to other students' opinions since the power is assigned to instructors. Students have to accept what the teacher says rather than to think by themselves. Moreover, Thai learners strongly believe that it is inappropriate to disagree with an instructor, and students should speak in class only when specifically called on by the teacher and generally should not offer comments to prevent the teacher and themselves from losing face. Both students and teachers avoid putting themselves in positions where they might lose face. Thus students are discouraged from speaking in class or using their initiative, which means that students are less likely to respond well to self-directed learning, which may connect with the perception that it is the instructor's task to design and direct the learning experience (Kamolpattana, et al., 2014). Consequently, students in such societies are less likely to acquire deep learning that results from more classroom involvement and the practical application of theory, which may lead the students in this culture to lack critical thinking skills (Chua \& Lateef, 2014).

\subsubsection{Individualistic/Collectivist Societies}

This dimension focuses on how people in a society define themselves as a part of a group, which can be determined by the degree to which people prefer to work alone or in a group. This represents the degree of social and community integration. Thailand has a score of 20 on the individualistic dimension, which represents a highly collectivist society. A collectivist culture tends to be socially hierarchical, and social interaction strongly focuses on groups who take care of each other in exchange for loyalty. Loyalty is the most important factor in this culture, which supports long-term commitment to group members. Thai people do not appreciate conflict with others. The culture is a face-saving and shaming culture with regard to punishment or domination because it is a highly collectivist culture which values social harmony. In contrast, individualistic cultures emphasize the importance of individual identity, human rights and needs rather than those of the group. This culture promotes self-efficiency and personal autonomy in a loose social framework. 
Collectivism and individualism are reflected in the learning styles of students and trainees. In the classrooms in individualistic societies, students are more likely to feel free to speak in class and are encouraged to think independently. Teachers encourage students to solve their own problems. These strategies tend to encourage students to become independent thinkers and doers, concentrating on their own individual needs and innovative approaches to problem solving, where independence and self-reliance are stressed and valued. Students are motivated to be involved in the learning process, are the center of the classroom, speak their mind in classroom discussions, and question their teachers. Teachers see disagreement as a part of learning. A good teacher is able to stimulate student interest, explain clearly, use effective instructional methods, and organize a range of activities. Therefore, teaching is not only viewed as transmitting knowledge from the teacher to students, but is also seen as the sharing and negotiation of knowledge and meaning. Interaction between students and teachers is encouraged in this social context.

In collectivist societies, especially where power distance in the classroom is high as in Thailand, students are not encouraged to express opinions and are expected to remember and recall what they have been told. Students are less likely to formulate and share their opinions or comments about what they learn in classrooms and seem to need more support, which means that independence and self-reliance are discouraged. Teachers stress the importance of recognizing the community hierarchy and the need to comply with norms rather than questions and debate. Thus, students in this kind of society tend to adopt a passive role, and the teaching is rather teacher-centered. Sharing opinions and knowledge is reserved for people with higher status. In contrast, classrooms in individualistic cultures emphasize personal responsibility for learning, which means students can self-direct and be more responsible for their learning than students in a collectivist society (Mahmoodi-Shahrebabaki, 2014). Hofstede (1986), suggested individualist students tend to possess more intrinsic motivation to study, that is, to pursue activities for the pleasure of the activity itself. However, the classroom interaction in a Thai context is where knowledge is transmitted by the teacher rather than discovered by learners, and where students are passive recipients of knowledge from teachers. Independence and self-confidence are not cultivated in these circumstances. Therefore, Thai learners have a tendency to lack analytical learning skills, which impacts their problem solving ability. Moreover, Thailand is a collectivist society where students tend to lack self-motivation and do not take responsibility for their study.

\subsubsection{Masculinity/Femininity}

A masculine society is driven by competition, achievement and success. Such cultures are characterized by power, assertiveness, dominance, and wealth and material success. A successful person will be the winner. In contrast, a feminine society focuses on what you do, caring for other people and the quality of life as the indicators of success. Thailand has a score of 34, which represents a feminine culture. However, Thailand has the lowest score of Asian countries, which have an average of 53. The world average is 50. The low score in this dimension implies Thai people are less motivated to compete than in other cultures.

Within the education context, students in a masculine culture are more likely to be goal driven. Competition to be the best in a class is encouraged and failing in school is considered as a major setback. The achievement of students is very important and involves challenging each other openly to show their strength and ability. Competition is regarded as useful in student learning because it can reinforce the goal structure of learning activities, which enhances students' motivation and learning achievement (Rienties, Luchoomun \& Tempelaar, 2014). Therefore, students in such societies are encouraged to compete with other students in terms of academic achievement. In contrast, in a feminine culture, being over-ambitious is not encouraged. Thus to put emphasis on encouraging students to compete against each other is discouraged and seen as a form of showing off (Dennehy, 2015).

Thailand is a feminine society and therefore lacks competition in education. Thai learners do not cultivate their self-motivation as an independent and creative learner, which includes self-learning to acquire more knowledge and to be ready for competition (Kaur, 2011). Furthermore, students have never been taught to learn by themselves because Thai education is social constructivist in nature, where knowledge is transmitted by the teacher rather than discovered by learners. Students are passive recipients of knowledge from teachers. Students are not experienced at learning as individuals using a constructivist paradigm (P. Pagram \& J. Pagram, 2006).

\subsubsection{Short-term and Long-term Orientation}

Short-term and long-term orientation refers to the degree to which members accept delayed gratification of their material, social, and emotional needs. Thailand scores 32 in this dimension, which suggests short-term orientation. People in such societies have an excessive respect for tradition, lack the tendency to save for the future, and focus on quick results.

With regard to short-term orientation, the education system does not encourage students to realize the benefits of deep learning, and mostly puts emphasis on practice and good behavior regarding the traditions of the culture. Education is a source of information and the context of education is to create long-lasting relationships which will be profitable in the 
future, both at a professional and personal level. These factors might tend to breed surface rather than deep learners. Students may concentrate only on their grades as their goal. In a long-term oriented culture, students may perceive the long-term goal as obtaining a good understanding of the subject, and hence work towards this goal, encouraging them to make a lot of effort to achieve their goals (Manikutty, Anuradha \& Hansen, 2007).

Thailand has a short-term orientation culture. Thai students care more about immediate gratification than long-term fulfillment Learning is more often seen as a one-time process which occurs mainly in the classroom, and studying out-of-class is neglected (Eaves, 2009). Moreover, Thailand focuses on closed-book examinations in which learners are required to remember information to pass examinations rather than to understand this knowledge to serve longer term purposes. They are only concerned about scores, results and grades but not future utility (Young, 2013).

Regarding Hofstede's cultural dimensions, the characteristics of Thai education can be classified as firstly, a teacher-centered education system in which the learner needs guidance. Learners are passive and expect to be told what to do and how to do it without question, and knowledge will be acquired from the teacher. It is inappropriate and impolite to question the teacher during the class as it shows a lack of respect. Consequently, learners lack critical thinking, problem solving and creative skills (Nguyen, 2011). Secondly, rote learning depends on tutors who provide information to students, so students are not encouraged to cultivate the necessary skills for self-learning. Thai learners show a lack of internal motivation to learn (Loima \& Vibulphol, 2014), so most students are passive learners rather than proactive learners. Thirdly, learning is more often considered as a one-time process, where students lack the willingness to learn at all times and in all places and therefore fail to understand the concept of ongoing and lifelong learning. Consequently, learning occurs mainly in class sessions whereas studying out-of-class is neglected (Eaves, 2009). Fourthly, based on particular cultural values, the Thai education system is test focused, which encourages Thai learners to put emphasis on memorization as opposed to deep understanding. The system, the method of teaching, the role of the student and the emphasis on final testing results in low levels of achievement in thinking ability and performance (Lu, Chin, Yao, Xu \& Xiao, 2010).

\subsection{Dissatisfaction with the Current ERP Training Approach}

The findings of an empirical study that was previously conducted by the researcher (Chayakonvikom, Fuangvut \& Prinyapol, 2016) indicated that most Thai end-users were dissatisfied with the current ERP training in four areas: the training method, the training content, the training and user manuals, and training time allocation, which are described in the following section.

\subsubsection{Training Method}

The training method most used for ERP training in a Thai context is classroom training. End-users were dissatisfied with the classroom training method because of the poor organization of lectures and practice during the training course. The whole training course was focused on lecturing but failed to give sufficient hands-on experience with the new system. End-users suggested the training method should pay more attention to practice or workshop by applying simulation training techniques based on real business work cases which match the organization's requirements rather than teaching by lecturing and demonstration using slides.

Another area of dissatisfaction with the current ERP training method was on-the-job training. This training method is widely used by key-users who are trained directly by ERP consultants. Key-users were trained to be trainers to train end-users. This training method is known as "train-the-trainer", and is recommended by ERP vendors such as SAP, Microsoft, Oracle etc. This training method is bundled into the ERP implementation methodology and is applied worldwide. Train-the-trainer is widely applied with large numbers of end-user organizations. The advantage of the train-the-trainer method is to reduce training costs, allowing the organization to arrange internal training for new employees. While this training method has a lot of advantages, to be trained by key-users is also a matter of concern. Key-users often lack the capability to transfer knowledge about how to use the ERP system properly, and are often unable to answer end-user questions on the business process and the various functions of the ERP system. Key-users acted as messengers rather than experts to transfer knowledge by referring end-user questions to ERP consultants.

\subsubsection{Training Content}

End-users were dissatisfied with the training content because it did not cover all end-user requirements and the particular organizational business processes. It was not sufficient to enhance end-users' knowledge to use the ERP system in real situations. Usually the training content taught only standard business processes but did not cover or apply the teaching to the particular organizational business processes. Suggestions about other useful content for example, special cases, unusual cases or sub details, apart from the standard processes, were not given. For this reason, end-users lack the capability to handle business cases other than the standard processes. End-users suggested that the training content should not be limited only to the parts of each end-user's responsibility, but that other content is important as 
well. For example, the fundamentals of the ERP system, the workflow and the relationships between each module in the ERP system including the data flow and cross functional business processes that explain the participants' role in each part of the ERP system should be included because this content helps to enhance end-user's understanding of the overall system. End users are involved in each part of the system and are the creators and users of the data. A broader understanding of the system would not only enhance end-users' understanding, but would also increase the end-users' problem solving capability too.

\subsubsection{Training and User Manuals}

End-users were dissatisfied with the format and content of the training and user manuals, which did not match their usage. The training and user manuals which end-users received were standard. The manuals were developed by several ERP vendors to be used in all organizations. Thereby the content is general and has the same pattern. The manual content is not designed based on end-user job characteristics and is not customized to be relevant to a particular organization's business processes. On many occasions, end-users found that the screen capture in the manual did not match the real screen of end-users, and the manual content focused only on the steps of how to use the ERP system, but did not include trouble-shooting and special techniques. From the learner's point of view, the user and training manuals were overloaded with content, included a lot of useless information and contained too many pages. It was therefore hard to find a problem solving solution immediately and they were not interested in reading it. The evidence indicates that most end-users hardly ever read the manual. The manual was not used as a tool for self-learning to increase end-user knowledge, or to find out how to use the ERP system properly, but was used on occasions only to solve problems. Furthermore, calling the support team to solve problems was the first choice rather than finding solutions in the manual by themselves. In particular, in some groups of end-users, people preferred to practice by employing trial and error in the system rather than reading the manual and preferred to develop individual manuals, which were based on lecture notes and screen captures, with step-by-step explanations and less technical jargon. This method was found to be easier for beginner users.

\subsubsection{Training Time Allocation}

End-users were dissatisfied with the poor training time allocation both in terms of the total amount of time and the periods of time for ERP training. Most end-users were pressured to learn how to use an ERP system in a short time which meant that the cognitive load (Chu, 2014) was too great. This means that the quantity of learning material was too large to be understood in a short space of time. As the ERP training has a lot of details to be learned, learning to use the ERP system with insufficient training time to gain hand-on experience does not enhance end-user confidence and familiarity when using the new system. The implementation plan, which was hurried to go-live, without considering the system usage capability, was said to be the cause of insufficient training time allocation. Importantly, the current ERP training was arranged in an inappropriate period of time. Usually training courses for an ERP project are arranged only at the end of the implementation period before the go-live stage. End-users expressed the opinion that training courses should not be provided in only one time period, but courses should be held before ERP training and after the go-live period too. The ERP training did not include training orientation. The training schedule was published for end-users, but nobody told them how they should prepare for training. Moreover, end-users did not have a chance to get involved in the training design process to indicate what they wanted to learn or which training method they preferred. Therefore, at the beginning of training, end-users did not clearly state what they want. After the go-live phase, end-users had usage experience of the new system which gave rise to new questions and issues that needed to be addressed in a subsequent training session.

\section{Method}

\subsection{Participant Characteristics and Sampling Procedures}

The participants are end-users who experienced ERP training during the period of project implementation. End-users who work closely with an ERP system are best placed to provide rich information on the current ERP training. The samples were selected from a list of ERP customer site references by employing a purposive and snowball sampling strategy. The list of ERP customer site references was acquired from ERP consulting companies in Thailand (non-public sources). The data qualities were verified by telephone and included duplicate data elimination. To achieve the research objective, the main study was constructed to test the research assumptions. Seventy-two end-users from twenty-two companies, including nine departments that had adopted an ERP system and had experience in ERP training during the period of the implementation phase in a Thai context were selected.

\subsection{Data Collection and Analysis}

A qualitative research approach was employed in this study to explore the cultural learning behavior of end-users. Qualitative research provides flexibility, allowing the researcher to deal with the data as it emerges during data 
collection and helps to provide the reader with real-life examples of what is being conveyed. Interview is an effective tool and is widely used to collect qualitative data. This helps the researcher to gather and understand people's opinions including suggestions, useful explanations or interpretations (Myers, 2009). Therefore, the in-depth face-to-face interview of individuals is appropriate for the research purpose of exploring the cultural learning behavior in the current ERP training in a Thai context. An interview guide that consisted of five open-ended questions was prepared. The interview guide was developed based on the pilot study results and literature review which was conducted earlier.

Content analysis is a strategy used for data analysis to identify themes that commonly occur. This is a way to characterize the learning behavior of Thai end-users in ERP training by using NVIVO software as a tool for "behavioral coding". Hofstede's cultural dimensions were used as the theoretical framework to explain the cultural learning behavior and any dissatisfaction with the current ERP training approach in a Thai context.

\section{Results}

The results of the in-depth interviews revealed the four cultural learning behaviors of Thai end-users in the current ERP training approach. Firstly, the reading behavior of Thai end-users was inadequate. Secondly, Thai end-users did not dare to ask questions especially in the training classroom even when they did not understand. Thirdly, Thai end-users lacked self-preparation for training. Fourthly, Thai end-users were found to lack the ability to practice by themselves outside the training class although computers were provided for self-practice. The example statements are shown in Table 1.

Table 1. Thai end-users learning behavior in the current ERP training approach

\begin{tabular}{|c|c|}
\hline & ample Statements \\
\hline $\begin{array}{l}\text { Lack of reading } \\
\text { behavior }\end{array}$ & $\begin{array}{l}\text { Respondent } 17 \text { "The manual explained too much deep in detail. I don't like to learn by reading and I am } \\
\text { lazy to read it because it is over loaded with information and made me confused. I only need to know what } \\
\text { the button that I have to push is. Can you tell me in short sentences please! Then I developed the manual in } \\
\text { my own style by taking notes. My personal manual is short notes which include how to operate the system } \\
\text { step by step without too much explanation. It is easier to memorize." } \\
\text { Respondent } 74 \text { "Although the manual is provided, I do not read it. I preferred to develop my own manual } \\
\text { based on practicing experience and then note it rather than reading the manual. Developing the manual } \\
\text { based on my understanding makes me realize more about the ERP system and it is easier to use it. I still } \\
\text { keep and use this manual until now." }\end{array}$ \\
\hline $\begin{array}{l}\text { Do not dare to ask } \\
\text { question }\end{array}$ & $\begin{array}{l}\text { spondent } 44 \text { "I found that during the training time, many end-users did not understand but they did not } \\
\text { questions to protect their face. Even though they did not understand they pretended to understand and } \\
\text { not ask questions. This is the advantage of Thai people which is fear to lose face and then they do not } \\
\text { spondent5 "The advantage of informal training such as on the job training is the good response of } \\
\text { l-users. They feel more comfortable to ask questions. This is totally different from classroom training in } \\
\text { ich they just listen and try to remember everything." }\end{array}$ \\
\hline $\begin{array}{l}\text { Lack } \\
\text { self-preparation }\end{array}$ & $\begin{array}{l}\text { spondent } 36 \text { "Self-Preparing for training? No, I do not prepare anything. I expect to be trained by the } \\
\text { iner to do everything and I just follow that." } \\
\text { spondent } 37 \text { "Most trainers prepare everything for training. For me, I do not prepare anything including } \\
\text { examples of my work case to do in the training classroom. In the first training, I just learned what they } \\
\text { ovided." }\end{array}$ \\
\hline $\begin{array}{l}\text { Lack the ability to } \\
\text { practice } \\
\text { themselves outside } \\
\text { the training class }\end{array}$ & $\begin{array}{l}\text { spondent } 23 \text { "Oh! Self-practicing outside training classroom! No, I don't do that becau } \\
\text { rk to do. Then after training I do not do self-study but mostly I learn based on actual u }\end{array}$ \\
\hline
\end{tabular}

\section{Findings and Discussion}

\subsection{Cultural Learning Behavior and dissatisfaction to the Current ERP Training Approach}

As noted earlier, the aims of this paper are to explore the cultural learning behavior of end-users in a Thai context, and to explain the issues and dissatisfaction about the current ERP training approach with reference to Hofstede's cultural dimensions. Thereby, the findings and discussion are presented in the following section.

\subsubsection{Training Method}

The results revealed the cultural learning behavior of end-users in the current ERP training by showing that Thai end-users lack the ability to practice by themselves outside the training class although computers were provided for self-practice. Practice occurred only in training sessions, and most end-users claimed that they did not have time for self-practice because of their extensive workload. Therefore, self-practice meant doing their job by using the new system after the go-live period. Furthermore, end-users did not have confidence to practice without the trainer. They lack the capability to solve problems by themselves. In addition, problems that occur outside the training may cause problems for the system, the database and other users.

According to Hofstede's cultural dimensions, Thailand is a feminine society and lacks competition in education. Thai 
employees tend to shun competitive learning. This issue has attracted an increasing amount of attention amongst education scholars. Thai employees do not develop as independent and creative learners through self-motivation, which means the ability for self-learning and preparation to acquire more knowledge is not cultivated (Loima \& Vibulphol, 2014). The findings reveal that pressure from the employers or supervisor to report the progress of training, including the measurement of end-user skills is a key factor to motivate end-users to practice outside the training classroom, so motivation is not self-generated. Furthermore, Thai education culture, with its high power distance and collectivism, produces employees who have never been taught to learn by themselves because Thai education is social constructivist in nature. Knowledge is transmitted from trainer to employee rather than discovered by employees, who adopt a passive role in class. Consequently, employees are not experienced at learning as individuals under a constructivist paradigm (P. Pagram \& J. Pagram, 2006). Moreover, Thai employees care more about immediate gratification than long-term fulfillment. Learning is more often seen as a one-time process where learning occurs mainly in the classroom and studying out-of-class is neglected (Eaves, 2009). Thai employees are not cultivated to study by themselves and lack self-motivation for, and awareness of, life-long learning.

This has serious implications for ERP training as learning how to use an ERP system requires self-learning to understand and master the system (Rajapakse \& Seddon, 2005). Thai end-users are unable and unwilling to do this. Furthermore, the classroom training method widely used by ERP consultants mainly teaches how to use the ERP system using slides, but lacks opportunities to practice and become familiar with the new system during the class. The poor organization of lectures and practice during the training course did not satisfy Thai end-users. Sufficient hands-on experience is an important factor to increase the confidence of employees to use the ERP system by themselves. Training is designed based on the understanding that end-users must employ self-learning to practice outside training class. This seems to be incompatible with Thai cultural learning behavior. For this reason, re-structuring the organization of lectures and practice during the training course to suit Thai end-users' learning behavior is necessary.

Furthermore, Thai end-users did not dare to ask questions especially in the training classroom, even when they did not understand. End-users were afraid to lose face in front of their colleagues. Thailand is a collectivist society, so employees are not encouraged to express opinions and are expected to remember and recall what they have been told, especially where the power distance in the classroom is high. Moreover, face-saving and "Kreng-Jai" are evident in a Thai hierarchical relationship, which requires acceptance without argument from a lower status individual to maintain a good self-image. This leads both trainers and trainees to avoid putting themselves in positions where they might lose face (Kamolpattana, Chen, Sonchaeng, Wilkinson, Willey \& Bultitude, 2014). This explains why end-users do not ask questions in classroom training. Therefore, the use of classroom training should be re-considered. However, the findings revealed that end-users feel more comfortable to ask questions with a trainer who encourages trainees to ask questions and does not make them lose face. On-the-job training is another option as end-users feel more comfortable to ask questions than in classroom training. On-the-job training provides opportunities for end-users and the trainer to work together more closely, which prevents both from losing face. Thailand is also a feminine culture, in which informal and personal communication, including face-to-face conversation, is preferred by Thai employees (Sellitto, 2015). The on-the-job training method is compatible with this behavior by focusing on practice based on real situations, so when end-users face problems, they can seek solutions when using the ERP system. This may reduce the fear to ask questions while end-users are gaining experience using the ERP system. The finding indicates that the fear to ask questions behavior changes when end-users have experience using the ERP system. End-users participated more, prepared and asked questions, and listed missing topics and contents for re-training. Thereby, an appropriate training method and technique should be adopted that encourages more classroom involvement for end-users, which may help to increase training efficiency in this culture.

On-the-job training allows end-users and the trainer to work closely and ask questions directly. However, the teaching capabilities of key-users are also a concern of end-users. Organizations employ key-users from different departments to be trainers and to assist other end-users in their department. This approach is known as the 'train-the-trainer' method. Developing in-house trainers helps an organization to save the cost of hiring external ERP consultants. It is difficult to develop key-users who have knowledge of both the existing business process and the ERP system. This is a limitation of the "train-the-trainer" method (Kumar, Maheshwari \& Kumar, 2003).

The Thai context is a high power distance society where people show loyalty and respect for superiors in exchange for protection and guidance. Therefore, key-users are selected based on reasons other than their suitability as a trainer. It was found that most key-users lacked the skill to transfer knowledge and had ERP system knowledge limitations. Furthermore, the education system in a high power distance society is largely a teacher-centered system, in which trainers are ranked higher than trainees in terms of society and their authority. Trainers are treated with respect as the experts to transfer knowledge, so end-users expect that their trainers should know everything. However, unqualified key-users and the poor selection process of key-users are problems of the "train-the-trainer" method in a Thai context. 
These reasons support why Thai end-users are dissatisfied with the "train-the-trainer" method provided by ERP vendors.

\subsubsection{Training Content}

Thai end-users lacked preparedness for training. Most end-users did not prepare anything based on the belief that it is the trainer's responsibility to prepare the training materials and training content to cover and suit the particular organizational processes. End-users were dissatisfied with the training content because it did not cover all end-user requirements and the particular organizational processes. It was not sufficient to enhance end-users' ability to use the ERP system in real situations. This problem became obvious when end-users had to deal with situations which were beyond the scope of what was taught in the training courses. Thai end-users did not participate in sharing information about the requirements for the training content, or the issues in their work about which the training should focus because they had no idea about the content that was necessary to help them to use the ERP system properly. Most end-users expressed the opinion that they had no ERP system experience. Therefore, it was difficult for them to share information including the preparation of data and business work case scenarios to use in the training session even though they realized that learning based on real data and business work case scenarios related to their work can help them to better understand how the ERP system works and to visualize how the existing business processes are replaced by the new business processes of the ERP system.

This is a problem in designing training content because it is not possible for ERP consultants to have a thorough knowledge of each organization's business processes. ERP consultants cannot prepare the training content to cover either the business processes or the specific conditions of each organization very well as it is impossible for an outsider to understand the specific business processes of each company. Therefore, the training content is designed based on the ERP consultant's perspective, which does not necessarily reflect end-user requirements. Thai employees have never been taught to learn by themselves because Thai education is social constructivist in nature, where knowledge is transmitted by the trainer rather than discovered by trainees. Thai education culture has high power distance and is rather teacher-centered. The employees are, therefore, passive recipients of knowledge from trainers. Consequently, Thai employees are not involved in preparing for the training. They believe that it is the trainer's responsibility to do this. Furthermore, Thailand is a feminine society and therefore lacks competition in education. Thai employees are not self-motivated to learn and do not take responsibility for their own progress in learning (Loima \& Vibulphol, 2014). These factors may explain why Thai end-users are not involved in preparing data and business work cases for training.

However, in a Thai context, management and project managers with experience of ERP implementation are important in motivating end-users to self-prepare for training so that end users can prepare data and business work cases to cover all of the important business processes, which could affect the efficiency of their training. Furthermore, the results reveal that end-users' behavior changed from passive to active after they had acquired some experience of using the ERP system. They could identify the parts they did not understand and the problems that might affect their work. This information motivated them to prepare data and questions to ask the trainer in training sessions when re-training was arranged.

The participation and self-preparation of end-users are necessary to design effective and useful training content. Thereby, working as a team is necessary to improve the quality of the training content. Good empathy and coordination between the trainer and the end-users is necessary to inform the objectives and benefits of preparing data and business work cases for training sessions, which affects the motivation of end-users to prepare for training in a Thai context.

\subsubsection{Training and User Manuals}

The results revealed that the reading behavior of Thai end-users was inadequate. They did not read the ERP training user manual. The manual was not used as a tool for self-study to increase ERP knowledge but was used when end-users needed to find a solution to problems or to remind them about some issues, which were not routine processes. However, finding the solution themselves by reading the manual was not the first choice of end-users. They preferred to acquire help from someone rather than searching in the manual themselves.

Both the training and the user manual did not satisfy Thai end-users because the format and content of the training and user manuals were not designed to support Asian end-users' usage behaviors. The current ERP training and user manual content were not designed based on end-users' job characteristics and were not customized to be relevant to a particular organization's business processes. Most of the content focused on explaining how to use the system step-by-step, but lacked guidance in trouble-shooting and problem-solving skills. From the end-user's point of view, the user and training manuals were overloaded with content and included a lot of useless information and too many pages. Some end-users expressed the opinion that finding the solution by searching in the manual took too long as it was hard to find the solution immediately, and they were not motivated to read it. Only the parts of interest were read in the manuals, but the other content was not read. Respondents mentioned that they did not like to learn by reading the manual because it had 
too much content, so learning by other methods was preferred.

Thai end-users did not realize the value of the training and user manuals. The manuals were not mentioned as a key factor in helping to enhance key-users' understanding and confidence to use the ERP system. Strauss (2008) mentioned that Thailand has no "reading culture". This is consistent with the National Statistics Survey (2013) which revealed that 44.08 percent of Thais do not read out of their study/work period because they dislike it and have no time for reading. Reading is the heart of self-education in acquiring knowledge and information to enhance the intellectual growth of a person (Benwari \& Nemine, 2014). In developing nations, including Thailand, where the education system is teacher-centered and employees are passive learners, employees are not prepared for self-learning. Moreover, learning is considered as a one-time process, while self-study out of class is often neglected. Employees lack self-motivation to acquire knowledge by themselves. Furthermore, studying by reading the user manual normally occurs outside the classroom, but Thai employees may not have the discipline to maintain a regular habit of reading. That is why Thai end-users prefer not to learn by reading the manual although learning how to use an ERP system requires self-learning to understanding and master the system (Rajapakse \& Seddon, 2005). Therefore, it is necessary to develop the training and user manuals to encourage end-users to read them.

\subsubsection{Training Time Allocation}

End-users were dissatisfied with the poor training time allocation both in terms of the amount time and the period of time for ERP training. Most end-users were pressured to learn how to use the ERP system in a short time period, which increased the cognitive load and did not enhance end-user's confidence and familiarity when using the new system. Learning how to use the ERP system involved learning a lot of details. Placing time limitations on the learning process, together with Thai end-users' inability and unwillingness to self-study and read outside the classroom meant that the learning of Thai end-users mainly occurred in the classroom. This explains why Thai end-users need more training time.

Furthermore, the current ERP training was arranged at an inappropriate time. Mostly, ERP training was arranged at the end of the implementation period before the go-live stage, but there was no training after the go-live period, which is important too. The current ERP implementation method and phase model was developed by ERP vendors and is mostly used by ERP consultants. This model focuses on the actual implementation phase (Jayawickrama, Liu \& Smith, 2014). However, the ERP project lifecycle is longer than that. Consequently, the importance of the phase model should be considered as well (Lawrence Norton, May Coulson-Thomas, Coulson-Thomas \& Ashurst, 2012). The current ERP training was designed to be conducted only once, but Thai end-users require direct experience using the ERP system to help them realize how the ERP system works. The level of experience is a key factor in changing end-users' learning behavior from passive to active learners. The current ERP training did not pay attention to training orientation, which could guide end-users to know how to self-prepare for training. End-users could not share ideas about the ERP training that they preferred because they had no ERP experience. Furthermore, the experience of ERP usage after the go-live period was useful too. This experience allows them to realize what the ERP training should be like and which training content should be covered, including the missing parts from the first training. Therefore, insufficient training time allocation and an inappropriate time period to arrange ERP training were problematic especially for Thai end-users, and should be reconsidered.

\section{Conclusion}

The findings support the assumption by demonstrating that the current ERP training approach did not accommodate Thai cultural learning behavior in many areas. The current ERP training approach was designed based on Western learning culture but is employed without concern for different learning cultures. Consequently, the current ERP training did not offer a training approach that can accommodate other learning cultures, including the Thai learning culture. This is overlooked by ERP vendors and also affected the effectiveness of training outcomes. The study of cultural background in education with reference to Hofstede's cultural dimensions to explain end-user dissatisfaction toward the current ERP training approach in this paper helped the researcher to describe the incompatibility of the current ERP training approach with the learning culture. This evidence will be used to develop an ERP instructional design framework, which should be culturally inclusive and able to accommodate various learning styles.

\section{References}

Aslam, M. Z. (2010). User Resistance In Post ERP Implementation Stage Lund University,

Bae, T. J., Qian, S., Miao, C., \& Fiet, J. O. (2014). The relationship between entrepreneurship education and entrepreneurial intentions: A meta - analytic review. Entrepreneurship Theory and Practice, 38(2), 217-254.

Benwari, N. N., \&Nemine, E. B. B. (2014). Intensive Reading As a Study Habit and Students' Academic Achievement in Economics in Selected Secondary Schools in Bayelsa State, Nigeria. Journal of Curriculum and Teaching, 3(2), 94-99. http://dx.doi.org/10.5430/jct.v3n2p94 
Chayakonvikom, M., Fuangvut, P., \& Prinyapol, N. (2016). The Incompatibility of End-User Learning Styles and the Current ERP Training Approach. International Journal of Information and Education Technology (IJIET), 6(6), 481-487. http://dx.doi.org/10.7763/IJIET.2016.V6.736

Chu, H. C. (2014). Potential Negative Effects of Mobile Learning on Students' Learning Achievement and Cognitive Load-A Format Assessment Perspective. Educational Technology \& Society, 17(1), 332-344.

Chua, J. S. M., \& Lateef, F. A. (2014). The flipped classroom: viewpoints in Asian Universities. Education in Medicine Journal, 6(4), 20-26. http://dx.doi.org/10.5959/eimj.v6i4.316

Dennehy, E. (2015). Hofstede and learning in higher level education: an empirical study. International Journal of Management in Education, 9(3), 323-339. http://dx.doi.org/10.1504/IJMIE.2015.070125

Dwivedi, Y. K., et al. (2015). Research on information systems failures and successes: Status update and future directions. Information Systems Frontiers, 17(1), 143-157. http://dx.doi.org/10.1007/s10796-014-9500-y

Eaves, M. (2009). Learning Styles Technology and Supporting Overseas Learners. Multicultural Education and Technology Journal 3(61-73. http://dx.doi.org/10.1108/17504970910951156

Hawari, A. A., \& Heeks, R. (2010). Explaining ERP Failure In Developing Countries: A Jordanian Case Study. The Journal of Enterprise Information Management, 23(2), 1-31. http://dx.doi.org/10.1108/17410391011019741

Hofstede, G. (1986). Cultural Differences in Teaching and Learning International Journal of Intercultural Relations, 10(3), 301-320. http://dx.doi.org/10.1016/0147-1767(86)90015-5

Jayawickrama, U., Liu, S., \& Smith, M. H. (2014). An ERP knowledge transfer framework for strategic decisions in knowledge management in organizations. International Journal of Innovation, Management and Technology, 5(4), 301. http://dx.doi.org/10.7763/IJIMT.2014.V5.530

Kamolpattana, S., Chen, G., Sonchaeng, P., Wilkinson, C., Willey, N., \& Bultitude, K. (2014). Thai visitors' expectations and experiences of explainer interaction within a science museum context. Public Understanding of Science, 24(1), 69-85. http://dx.doi.org/10.1177/0963662514525560

Kaur, A. (2011). Effects of Teacher Autonomy Support Intervention on Thai Students' Motivation: A Self Determination Theory Perspective (Doctoral Dissertation, University of Utara, Malaysia). Retrived from http://etd.uum.edu.my

Kilic, H. S., Zaim, S., \& Delen, D. (2015). Selecting “The Best” ERP system for SMEs using a combination of ANP and PROMETHEE methods. Expert Systems with Applications, 42(5), 2343-2352. http://dx.doi.org/10.1016/j.eswa.2014.10.034

Kumar, V., Maheshwari, B., \& Kumar, U. (2003). An investigation of critical management issues in ERP implementation: emperical evidence from Canadian organizations. Technovation, 23(10), 793-807. http://dx.doi.org/10.1016/S0166-4972(02)00015-9

Lawrence, N. A., May Coulson-Thomas, Y., Coulson-Thomas, C. J., \&Ashurst, C. (2012). Delivering training for highly demanding information systems. European Journal of Training and Development, 36(6), 646-662. http://dx.doi.org/10.1108/03090591211245530

Loima, J., \& Vibulphol, J. (2014). Internal interest or external performing? A qualitative study on motivation and learning of 9th graders in Thailand basic education. Journal of Education and Learning, 3(3), 194. http://dx.doi.org/10.5539/jel.v3n3p194

Lu, J., Chin, K., Yao, J., Xu, J., \& Xiao, J. (2010). Cross-Cultural Education: Learning Methodology and Behaviour Analysis for Asian Students in IT Field of Australian Universities. Proceedings of Australasian Computing Education Conference (ACE 2010) 103, 117-125.

Mahmoodi-Shahrebabaki, M. (2014). E-learning in Iran as a developing Country: Challenges Ahead and Possible Solutions. International Journal of Research in Education Methodology, 6(2), 788-795. http://dx.doi.org/10.2139/ssrn.2514434

Manikutty, S., Anuradha, N. S., \& Hansen, K. (2007). Does Culture Influence Learning Styles in Higher Education? International Journal of Learning and Change, 2(1), 70-87. http://dx.doi.org/10.1504/IJLC.2007.014896

Marambe, K. N., Vermunt, J. D., \& Boshuizen, H. P. A. (2012). A Cross-Cultural Comparision of Student Learning Patterns in Higher Education. Higher Education, 64(3), 299-316. http://dx.doi.org/10.1007/s10734-011-9494-z

Meissonier, R., Houze, E., \& Bessiere, V. (2013). Cross-Cultural Frictions in Information System Management: Research Perspectives On ERP Implementation Misfits in Thailand. International Business Research 6(2), 150-159. http://dx.doi.org/10.5539/ibr.v6n2p150 
Myers, M. D. (2009). Qualitative Research in Business \& Management Los Angeles, SAGE Publications Ltd.

Nguyen, C. T. (2011). Challenges of Learning English in Australia Towards Students Coming from Selected Southeast Asian Countries: Vietnam, Thailand and Indonesia. International Education Studies, 4(13-20. http://dx.doi.org/10.5539/ies.v4n1p13

Office, T. N. S. (2013). The Reading of Population Survey 2013. Thailand: Retrieved from http://www.nso.go.th.

Pagram, P., \& Pagram, J. (2006). Issues in E-Learning: A Thai Case Study. The Electronic Journal on Information Systems in Developing Countries (EJISDC), 26(6), 1-8.

Rajapakse, J., \& Seddon, P. B. (2005). ERP Adoption in Developing Countries in Asia: A Cultural Misfit. Proceedings of Information System Seminar in Scandinavia, 1-18.

Ram, J., \& Corkindale, D. (2014). How "critical” are the critical success factors (CSFs)? Examining the role of CSFs for ERP. Business Process Management Journal, 20(1), 151-174. http://dx.doi.org/10.1108/BPMJ-11-2012-0127

Rienties, B., Luchoomun, D., \& Tempelaar, D. (2014). Academic and social integration of Master students: a cross-institutional comparison between Dutch and international students. Innovations in education and teaching international, 51(2), 130-141. http://dx.doi.org/doi:10.1080/14703297.2013.771973

Sellitto, C. (2015). User intentions to adopt mobile payment services: A study of early adopters in Thailand. Journal of Internet Banking and Commerce, 20(1),

Shahin, A., Sadri, S., \& Gazor, R. (2010). Evaluating The Application of Learning Requirements Planning Model in The ERP Project of Esfahan Steel Company. International Journal of Business and Management, 5(2), 33-43. http://dx.doi.org/10.5539/ijbm.v5n2p33

Strauss, M. J. (2008). Reading Habits and Attitudes of Thai L2 Students (Master's thesis, University of South Africa, South Africa). Retrived from http://umkn-dsp01.unisa.ac.za

Young, D. (2013). Perspectives on cheating at a Thai University. Language Testing in Asia, 3(1), 1-15. http://dx.doi.org/10.1186/2229-0443-3-6

\section{$(\mathrm{cc}) \mathrm{BY}$}

This work is licensed under a Creative Commons Attribution 3.0 License. 